\title{
Flux Weakening Control of Permanent Magnet Machine Based Aircraft Electric Starter-Generator
}

\author{
S. Bozhko, M. Rashed, S.S.Yeoh, T. Yang, and C. Hill \\ Department of Electrical and Electronics Engineering, University of Nottingham, Nottingham, UK \\ E-mail:serhiy.bozhko@nottingham.ac.uk
}

Keywords: Starter, Generator, Control, Flux-weakening, Design.

\begin{abstract}
This paper presents control analysis and design for an aircraft electric starter-generator system based on a Permanent Magnet Machine (PMM) operated in Flux-Weakening mode (FW). The focus is on detailed stability analysis which helped to discover an intrinsic instability when operating the PMM in FW mode. An adaptive voltage magnitude controller, including a variable current limit, is proposed and shown to guarantee stable operation. The analytical findings are verified by experimental investigation.
\end{abstract}

\section{Introduction}

Many aircraft system technologies are undergoing major changes due to a global tendency towards environmentally responsible air transportation. The state-of-the art on-board systems are expected to be more efficient, safer, simpler in servicing and easier in maintenance [1], [2]. As a result, many existing hydraulic and pneumatic power driven systems are being replaced by their electrical counterparts. This trend is known as a move towards the "More Electric Aircraft" (MEA) in which a large number of new electrical loads have been introduced. Therefore electric power generation systems have a key role in supporting this technological trend.

The current starter/generator $(\mathrm{S} / \mathrm{G})$ technology employs a threestage wound-field synchronous machine. However, performing a starter function requires an additional winding hence compromising the overall system weight and adding complexity to the machine. Advances in modern power electronics now allow the developers to consider including other machine types within the $\mathrm{S} / \mathrm{G}$. This results in substantial improvements in power density $(\mathrm{kW} / \mathrm{kg})$ and overall system performance. One of the potential solutions is to employ a permanent magnet machine (PMM) in future S/G systems. However, operation of a PMM at high speed, with limited dc bus voltage, requires operation in Flux-Weakening (FW) mode [[3]]-[5]. It has been found that rigorous control design for PMMs in generation and FW mode has not been studied in enough details, hence the paper addresses this gap.

There are many control strategies presented within literature for FW of PMM. Among them is the voltage magnitude control strategy [6], [8]-[[9]], where the reference flux current is directly controlled by the voltage controller while the torque current reference dynamically limited in order to satisfy the current limit $I_{\max }$. The voltage controller is applied to provide the phase angle of the PMM reference current vector [11], however it is designed for motoring mode only. Another FW voltage control approach is presented in [7], [12]: here the voltage angle is determined by a single current controller, while the voltage magnitude is set to the maximum output value from the converter. In [7], the d-axis current controller is used for motoring mode and the voltage control loop is switched to the q-axis current controller in generating mode. The drawbacks of this approach are poor stability and the requirement of mechanisms to change the control between constant torque and FW mode. In [12], modifications to this control are proposed to achieve smooth transition. However, the focus of [7-12] was on motoring mode.

This paper reports a detailed analysis and control design of FW control for PMM-based starter-generator addressing both generating and motoring modes. Potentially unstable area of operation is identified and an adaptive current limitation and voltage controller are designed to stabilize the control system.

\section{PMM Plant Model}

The control system of this study is depicted in Fig. 1. The controlled plant includes the PMM and associated converter. The PMM is considered in the synchronously rotating dq reference frame with the $d$ axis aligned to the machine rotor [[3]], [[4]]. The PMM model is given as [[3]], [13]:

$$
\begin{aligned}
& L_{d} \frac{d}{d t} i_{d}=-R_{s} i_{d}+\omega_{r e} L_{q} i_{q}+v_{d} \\
& L_{q} \frac{d}{d t} i_{q}=-R_{s} i_{q}-\omega_{r e} L_{d} i_{d}-\omega_{r e} \psi_{r}+v_{q} \\
& J \frac{d}{d t} \omega_{r}=K_{m}\left[\psi_{r} i_{q}+\left(L_{d}-L_{q}\right) i_{d} i_{q}\right]+T_{l} \\
& T_{l}=f\left(\omega_{r}\right)
\end{aligned}
$$

where: $v_{d}, v_{q}, i_{d}$ and $i_{q}$ are the $\mathrm{d}$ and q-axis voltage and current components and the positive current is the current flowing into the machine. $R_{s}, L_{d}$ and $L_{q}$ are the stator resistance and inductances, $\omega_{r}$ and $\omega_{r e}\left(\omega_{r e}=p_{p} \omega_{r}\right)$ are the mechanical and electrical rotor speeds, $\psi_{r}$ is the permanent magnet flux. $K_{m}$ is the machine constant, $K_{m}=3 p_{p} / 2 . p_{p}$ is the PMM number of pole pairs. $J$ is the system inertia. $T_{l}$ is the load torque. The system parameters used in this study are given in Appendix I.

Typically, the operation of the PMM is limited by the maximum output current $I_{\max }$ and voltage available from the converter. These limits are obeyed in the PMM control system such that the machine current is limited to $I_{\max }$. and the machine voltage is controlled to avoid converter overmodulation.

The PMM current and stator voltage magnitude are controlled using classical cascaded control loops (Fig. 1). The current controls employ PI controllers designed for $400 \mathrm{~Hz}$ bandwidth at 
$\zeta=0.95$. In FW mode, the outer voltage controller $\left(V_{\text {cont }}\right)$ is controlling the PMM stator voltage via $i_{d-r e f}$. The value of $i_{q-r e f}$ (torque control) is set to either $i_{q \text {-limited }}^{*}$ or $i_{q \text {-unlimited. This }}^{*}$ strategy results in two modes of operation; limited $i_{q}$ mode and unlimited $\mathrm{i}_{\mathrm{q}}$ mode. In the limited $\mathrm{i}_{\mathrm{q}}$ mode, a current limiter is used to determine $i^{*}{ }_{q \text {-limited }}$ based on the values of $I_{\max }$ and $i_{d \text {-ref. }}$. However, in the unlimited $\mathrm{i}_{\mathrm{q}}$ mode, $\mathrm{i}_{\mathrm{q}-\text { ref }}$ is set independent of $i_{d-r e f}$ and is equal to $i_{\text {q-unlimited. }}$

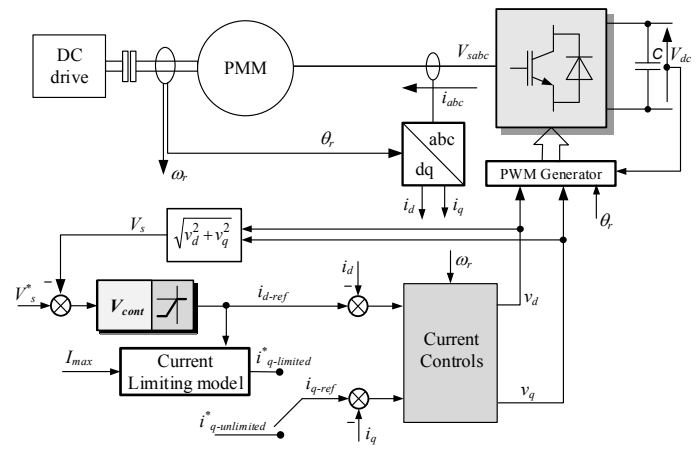

Fig. 1 The overall control system of the PMM.

\section{Flux-weakening Control Loop Analysis}

In FW the stator voltage magnitude $\mathrm{V}_{\mathrm{s}}$ is controlled to match the maximum output voltage from the converter $V_{s}^{*}$. The voltage magnitude is derived as:

$$
V_{s}=\sqrt{v_{d}^{2}+v_{q}^{2}}
$$

The $V_{s}$ value is compared to $V_{s}^{*}$ and the error is processed by the voltage controller producing $i_{d-r e f}$. The machine torque is controlled by $i_{q-r e f}$ within maximum current limit $I_{\max }$. The priority is given to $i_{d-r e f}$ hence::

$$
i_{q-r e f} \leq \sqrt{I_{\text {max }}^{2}-i_{d-r e f}^{2}}
$$

When current limitation is activated, $i_{q}$ follows the reference value calculated by (3) and hence it depends on $i_{d-r e f}$. In this mode, $i_{d-r e f}$ alone defines the active and reactive power provided to the PMM by the converter. The two current control modes will now be subjected to detailed analysis.

\subsection{Voltage control loop analysis in unlimited $i_{q}$ mode}

The model of voltage control loop is clearly nonlinear hence it was linearized for small signal analysis and control design. The small-signal model for (2) is given as:

$$
\Delta V_{s}=\frac{v_{d}^{0}}{V_{s}^{0}} \Delta v_{d}+\frac{v_{q}^{0}}{V_{s}^{0}} \Delta v_{q}
$$

where $\quad \Delta v_{d}=\left(R_{s}+L_{d} s\right) \Delta i_{d}-\omega_{r e}^{0} L_{q} \Delta i_{q}-i_{q}^{0} L_{q} \Delta \omega_{r e} \quad$ and $\Delta v_{q}=\left(R_{s}+L_{q} s\right) \Delta i_{q}+\omega_{r e}^{0} L_{d} \Delta i_{d}+\left(i_{d}^{0} L_{d}+\psi_{r}\right) \Delta \omega_{r e} \quad$ and $\Delta \omega_{\text {re }}$ is derived from (1) as:

$$
\begin{aligned}
& (J s) \Delta \omega_{r}=K_{m}\left(\psi_{r} \Delta i_{q}+\left(L_{d}-L_{q}\right)\left(i_{d}^{0} \Delta i_{q}+i_{q}^{0} \Delta i_{d}\right)\right)+\Delta T_{l} ; \\
& \Delta T_{l}=T_{l}^{0} \Delta \omega_{r} ; \quad T_{l}^{0}=\left.\frac{\partial f\left(\omega_{r}\right)}{\partial \omega_{r}}\right|^{0}
\end{aligned}
$$

Variables indexed with zero denote their steady-state value around the selected linearization point. From (4), one can obtain the small signal Open Loop Transfer Function (OLTF) $\Delta V_{s} / \Delta i_{d}$ by considering $i_{q}$ and $\omega_{r e}$ as disturbances:

$$
\frac{\Delta V_{s}}{\Delta i_{d}}(s)=\frac{1}{V_{s}^{0}} \frac{a_{2} s^{2}+a_{1} s+a_{0}}{b_{1} s+b_{0}}
$$

where $a_{0}, a_{1}, a_{2}, b_{0}$ and $b_{1}$ are constant coefficients depending on operational point. The transfer function (5) has two zeros and one pole. However, for special cases when the PMM is surfacemounted (SPMM), i.e. $\mathrm{L}_{\mathrm{d}}=\mathrm{L}_{\mathrm{q}}$, or when the machine is assumed connected to a constant speed shaft the TF (5) can be reduced to (6) with only one zero:

$$
\frac{\Delta V_{s}}{\Delta i_{d}}(s)=\frac{1}{V_{s}^{0}}\left[L_{d} v_{d}^{0} s+\left(R_{s} v_{d}^{0}+L_{d} v_{q}^{0} \omega_{r}^{0}\right)\right]
$$

The small signal model (4)-(6) of the voltage control loop is represented by the block diagram shown in Fig. 2.

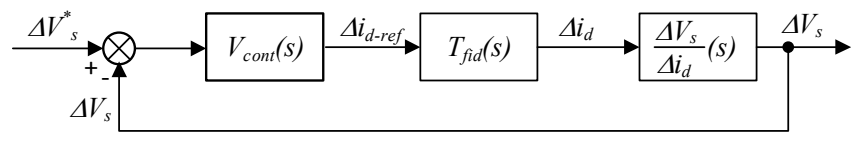

Fig. 2 Block diagram of the voltage control loop small signal model.

All zeros and poles of the system Fig. 2 are fixed except the zero of TF (6), which changes position on the s-plane depending on the PMM operation, i.e. motoring mode or generation mode. From (6), the operating points at which the zero jumps from the left-side to the right-side of the s-plane occur at $v_{d}=0$ hence when:

$\frac{i_{q}^{0}}{i_{d}^{0}}=\frac{i_{q-r e f}}{i_{d-r e f}}=\frac{R_{S}}{\omega_{r e} L_{q}}$

This effect results in a non-minimum phase control loop in motoring mode; therefore a careful control design is required. Figure 3 illustrates the trajectories of the system zeros for a PMM in FW for different speeds and $i_{q}$ currents.

Based on (7) and the results shown in Fig. 3, the voltage controller is designed for the worst case scenario, i.e. when the voltage control loop is non-minimum phase at large $\mathrm{i}_{\mathrm{q}}^{0}$ in motoring mode. At this design conditions, the zero is close to the origin of the s-plane and nearly independent of the motor speed (see Fig. 3, the trajectories converge at high $\mathrm{i}_{\mathrm{q}}^{0}$ ).

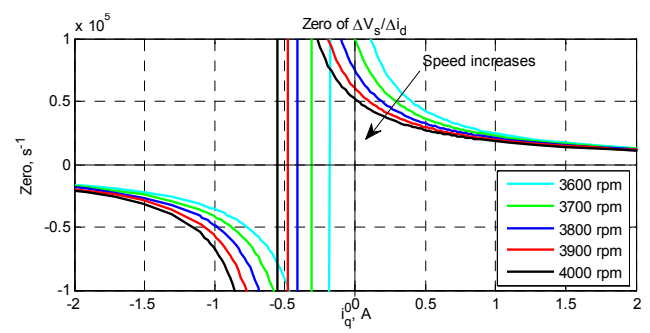

Fig. 3 The trajectory of the zero of the TF (6) in unlimited $i_{q}$ mode.

For the purpose of voltage control design, the poles and zeros of the $\mathrm{TF} \Delta \mathrm{V}_{\mathrm{s}} / \Delta \mathrm{i}_{\mathrm{d}-\mathrm{ref}}$ are first calculated for the following conditions: $3600 \mathrm{rpm}, \mathrm{i}_{\mathrm{q}}^{0}=8 \mathrm{~A}$ (the $i_{q}$ nominal value), and $V_{s}=$ $250 \mathrm{~V}$; these are listed in Table 1. 
Table 1 Zeros and poles of $\Delta \mathrm{V}_{\mathrm{s}} / \Delta \mathrm{i}_{\mathrm{d}-\text { ref }}\left(i_{q}^{0}=8 \mathrm{~A}, 3600 \mathrm{rpm}, V_{s}=250 \mathrm{~V}\right)$

\begin{tabular}{|c|c|c|}
\hline$Z_{1}$ & $Z_{2}$ & $\mathrm{P}_{1,2}$ \\
\hline 3132.2 & -686.2 & $-1128.8 \pm 362.3 \mathrm{i}$ \\
\hline
\end{tabular}

Based on the positions of $Z_{1}, Z_{2}$ and $P_{1,2}$, it is found sufficient to use only an integral voltage controller. The corresponding root locus of the loop is given in Fig. 4. The controller gain $k_{i v}$ should not exceed 396 and selected value is $\mathrm{k}_{\mathrm{iv}}=100$ The CLTF poles at $\mathrm{k}_{\mathrm{iv}}=100$ are marked by red crosses in Fig. 4.

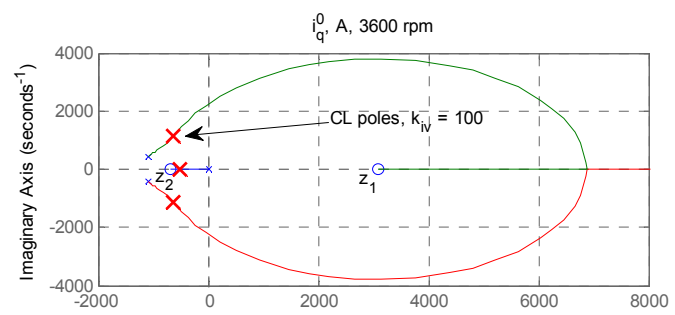

Fig. 4 Root locus of the voltage control loop with integral voltage controller in unlimited $\mathrm{i}_{\mathrm{q}}$ mode.

\subsection{Voltage control loop analysis in limited $i_{q}$ mode}

Dynamic $i_{q-\text { ref }}$ limitation can occur when the PMM is requested to produce large torque in $\mathrm{FW}$ (either in motoring or in generating mode). As soon as the speed exceeds the nominal value, $i_{q-r e f}$ must be reduced to satisfy the current limit (3). This will result in the following small signal model:

$$
\frac{\Delta i_{q-r e f}}{\Delta i_{d-r e f}}=\frac{-i_{d-r e f}}{\sqrt{I_{\text {max }}^{2}-i_{d-r e f}^{2}}}=-\frac{i_{d}^{0}}{i_{q}^{0}}
$$

Using (4) and (8), one can derive for the limited $i_{q}$ mode:

$$
\frac{\Delta V_{s}}{\Delta i_{d}}(s)=\frac{1}{i_{q}^{0} V_{s}^{0}} \frac{a_{2} s^{2}+a_{1} s+a_{0}}{b_{1} s+b_{0}}
$$

where $a_{0}, a_{1}, a_{2}, b_{0}$ and $b_{1}$ are constant coefficients depending on operational point.

For the analysis, the TF of $\mathrm{i}_{\mathrm{q}}$ and $\mathrm{i}_{\mathrm{d}}$ control loops assumed identical. Under the constant speed, TF (9) is reduced to:

$$
\frac{\Delta V_{s}}{\Delta i_{d}}(s)=\frac{1}{i_{q}^{0} V_{s}^{0}}\left(a_{2} s+a_{1}\right)
$$

The reduced order TF (10) has only one zero; the trajectories of this zero at different operating speeds are shown in Fig. 5:

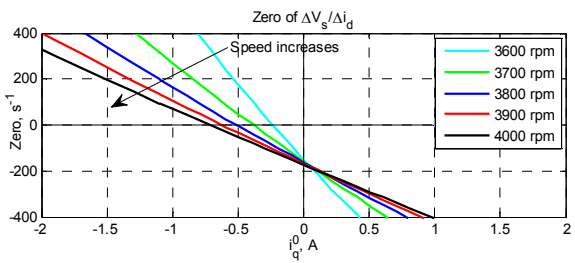

Fig. 5 The trajectory of the zero of the TF (10) for limited $i_{q}$ mode

Contrary to the zero of TF (6), the zero of (10) is on the rightside of the s-plane in generating mode. As such, the voltage control loop will change from being a minimum phase to a nonminimum phase when the current control mode is changed from unlimited to limited $\mathrm{i}_{\mathrm{q}}$ mode or vice versa. Therefore, the transition between the control modes on the voltage control should be considered when selecting the design value of $\mathrm{k}_{\mathrm{iv}}$.
The trajectories in Fig. 5 show that the zero moves towards the origin with a decreasing $i_{q}$. As a result the voltage control loop can go unstable if the integration gain $\mathrm{k}_{\mathrm{iv}}$ remains 100 . In practice, operation of the system at small $\mathrm{i}_{\mathrm{q}-\mathrm{ref}}$ in limited $\mathrm{i}_{\mathrm{q}}$ mode is a rare practical situation. Let us assume for the purpose of analysis that $\mathrm{I}_{\max }$ is intentionally reduced to a small value in generating, for example - to $1.64 \mathrm{~A}$; hence $\mathrm{i}_{\mathrm{q}}^{0}=1 \mathrm{~A}$ at $3600 \mathrm{rpm}$ and $V_{s}=250 \mathrm{~V}$. The root locus for this case is shown in Fig. 6: this highlights the unstable CLTF poles for $\mathrm{k}_{\mathrm{iv}}=100$ (marked in red crosses). Hence the need to use adaptive $\mathrm{k}_{\mathrm{iv}}$ gain.

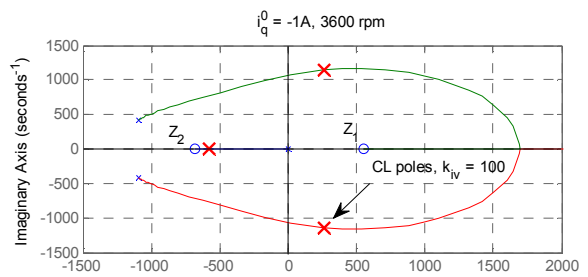

Fig. 6 Root locus of voltage control loop for limited $i_{q}$ mode.

\section{Voltage controller design}

The analysis in the previous section shows that in order to maintain stable operation in limited $\mathrm{i}_{\mathrm{q}}$ and generating mode, $\mathrm{k}_{\mathrm{i}}$ should be adaptively changing. In order to determine the stability boundary limits for $\mathrm{k}_{\mathrm{iv}}$, the Routh Hurwitz criterion is applied to the closed-loop TF of the voltage loop. From (6) and (10), the open-loop TF is expressed in a general form as:

$$
O L T F_{v s}=\frac{k_{i v}}{s} T_{f i d}(s) \frac{\Delta V_{s}}{\Delta i_{d}}(s)
$$

where $T_{f i d}(s)=\frac{G_{i}\left(s-z_{i}\right)}{\left(s-p_{i 1}\right)\left(s-p_{i 2}\right)}$ and $\frac{\Delta V_{s}}{\Delta i_{d}}(s)=G_{v}\left(s-Z_{v}\right)$.

$\mathrm{G}_{\mathrm{i}}, \mathrm{Z}_{\mathrm{i}}, \mathrm{P}_{\mathrm{i} 1}, \mathrm{P}_{\mathrm{i} 2}$ are the gain, zero and poles of $T_{f i d}(s) . G_{v}$ and $Z_{v}$ are the gain and the zero of $\Delta V_{s} / \Delta i_{d}$ obtained from (6) and (10) for unlimited and limited $\mathrm{i}_{\mathrm{q}}$ modes. Hence, the characteristic equation of the voltage control loop is given by:

$c_{3} s^{3}+c_{2} s^{2}+c_{1} s^{1}+c_{0}=0$

where $c_{0}=k_{i v} G_{i} G_{v} Z_{i} Z_{v}, c_{1}=p_{i 1} p_{i 2}-k_{i v} G_{i} G_{v}\left(Z_{i}+Z_{v}\right)$, ; $c_{2}=k_{i v} G_{i} G_{v}-p_{i 1}-p_{i 2}$ and $c_{3}=1$.

The Routh stability conditions for (12) to be stable are: $c_{3}, c_{2}, c_{1}$ and $c_{0}$ should be $>0$ and $c_{2} c_{1}>c_{3} c_{0}$. Hence, for a stable voltage control loop, the range of $\mathrm{k}_{\mathrm{iv}}$ should be bounded by the limits obtained from (12) as:

$k_{i v-l m t 1}=\frac{p_{i 1}+p_{i 2}}{G_{i} G_{v}}$

$k_{i v-l m t 2}=\frac{p_{i 1} p_{i 2}}{G_{i} G_{v}\left(Z_{i}+Z_{v}\right)}$

$k_{i v-\operatorname{lm} t 3}=\operatorname{sgn}\left(G_{i} G_{v} Z_{i} Z_{v}\right)$

$A k_{i v}^{2}+B k_{i v}+C=0$

where $A=-G_{i}^{2} G_{v}^{2}\left(Z_{i}+Z_{v}\right) ; C=-\left(p_{i 1}+p_{i 2}\right) p_{i 1} p_{i 2}$ and $B=$ $G_{i} G_{v}\left[\left(Z_{i}+Z_{v}\right)\left(p_{i 1}+p_{i 2}\right)-Z_{i} Z_{v}+p_{i 1} p_{i 2}\right]$

The four equations in (13) give five boundary limits. Three of these boundary limits are obtained from (13a-c) $k_{i v-l m t l-3}$ and two $k_{i v-\operatorname{lm} t 4}$ and $k_{i v-\operatorname{lm} t 5}$ are obtained from the solution of (13d):

$$
k_{\text {iv-limt } 4}=\frac{1}{2 A}\left(-B-\sqrt{B^{2}-4 A C}\right)
$$




$$
k_{\text {iv-limt } 5}=\frac{1}{2 A}\left(-B+\sqrt{B^{2}-4 A C}\right)
$$

The range of $k_{\text {iv }}$ for stable operation is bounded by these five boundary limits as depicted in Fig. 7.

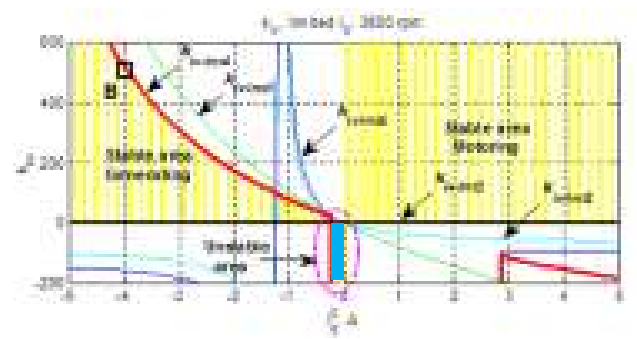

Fig. $7 \mathrm{k}_{\mathrm{iv}}$ range for stable operation in limited $\mathrm{i}_{\mathrm{q}}$ mode.

The range of $\mathrm{k}_{\mathrm{iv}}$ for stable operation is highlighted in yellow for all operating points at $\omega_{\mathrm{r}}=3600 \mathrm{rpm}, \mathrm{V}_{\mathrm{s}}=250 \mathrm{~V}$. Note that for any positive $\mathrm{k}_{\mathrm{iv}}$ in motoring the voltage loop is stable. However, $\mathrm{k}_{\mathrm{iv}}$ is limited by the $\mathrm{k}_{\mathrm{iv}-\mathrm{lm} t}$ trajectory (14-a) in generating (red line in Fig. 7). The limit $k_{i v-l m t 4}$ decreases with decreasing $i_{q}$ until $\mathrm{i}_{\mathrm{q}}$ reaches a critical value at which $\mathrm{k}_{\mathrm{iv}}$ has to be changed to a negative value to maintain stable operation. At this critical $i_{q}$ value the zero-trajectory in Fig. 5 crosses the zero line. The critical value of $i_{q}$ is obtained from (10) by solving the quadratic equation $\mathrm{a}_{1}=0$ to obtain $\mathrm{i}_{\mathrm{q}}$. In order to simplify the solution, the resultant quadratic equation is reduced to a first order equation by assuming the saliency of the PMM is small enough to replace $\mathrm{L}_{\mathrm{d}}$ and $\mathrm{L}_{\mathrm{q}}$ by the average value of the PMM inductance, i.e. $\mathrm{L}_{\mathrm{av}}=$ $0.5\left(\mathrm{~L}_{\mathrm{d}}+\mathrm{L}_{\mathrm{q}}\right)$. This is substituted into $\left(\mathrm{a}_{1}=0\right)$ and solved as:

$$
i_{q-c r t} \sim \frac{R_{s} i_{d}^{0}}{0.5 \omega_{r e}\left(L_{d}+L_{q}\right)}
$$

The (15) is the current at which the sign of $\mathrm{k}_{\mathrm{iv}}$ is required to become negative in order to maintain stable operation. This is difficult to implement in a practical system since $i_{q-c r t}$ is dependent on the PMM parameters which can vary during operation. The more practical scenario is to avoid operating the PMM in the unstable area, i.e. when in generating and limited $\mathrm{i}_{\mathrm{q}}$ mode and $\left|\mathrm{i}_{\mathrm{q}}\right|$ is less than $\left|\mathrm{i}_{-\mathrm{crtr}}\right|$. The unstable area of operation is highlighted in "blue" in Fig. 7. For the stable areas of operation in generating and limited $i_{q}$ mode, the value of $k_{i v}$ is adaptively set equal to half the value of boundary limit $k_{i v-l m t 4}(14 \mathrm{a})$ and when $k_{i v-l m t 3}>0$. The adaptive $\mathrm{k}_{\mathrm{iv}}$ is given as:

$$
k_{i v \text {-adapt }}=\frac{1}{2} k_{i v-l i m t 4} ; \text { with } k_{i v-l m t 3}>0
$$

To avoid the unstable operating area by a sufficient margin, $I_{\max }$ should be high enough so that the resultant $i_{\text {q-ref }}$ from (3) is larger than $2 i_{q-c r t}(15)$. This condition is fulfilled by:

$$
I_{\text {max }}>I_{l m t}, \quad I_{l m t}^{2}=\left[i_{d-r e f}^{2}+\left(2 i_{q-c r t}\right)^{2}\right]
$$

The range of $k_{i v}$ for stable operation in unlimited $i_{q}$ mode is also calculated at $3600 \mathrm{rpm}$ and highlighted in yellow in Fig. 8. It is noted that $\mathrm{k}_{\mathrm{iv}}$ is always positive and can be set as high as possible in generating mode. In motoring mode, the limit decreases with increase in $i_{q}$. However, in this case the limit is still high enough to allow selecting $\mathrm{k}_{\mathrm{iv}}$ values to provide good dynamic performance.

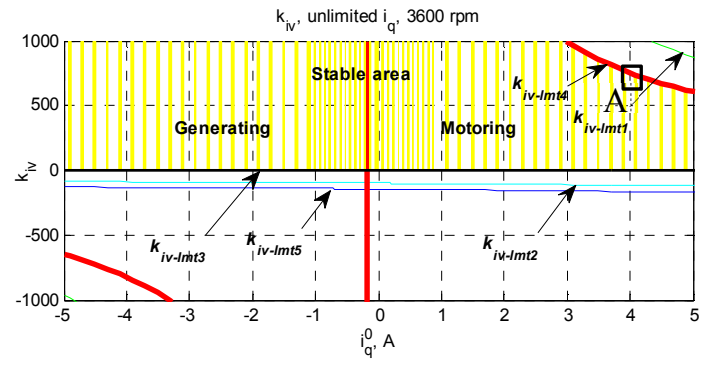

Fig. $8 \mathrm{k}_{\text {iv }}$ range for stable operation in unlimited $\mathrm{i}_{\mathrm{q}}$ mode

\section{Proposed Current Limiting Strategy}

The analysis in the previous section shows that the voltage control loop is unstable when in limited $i_{q}$ and generating mode. In fact, this instability is a natural result of using the $\mathrm{i}_{\mathrm{q}-\text {-ref }}$ limitation (3), which results in a varying gradient of $i_{q-\text { ref }}$ with respect to $i_{d-\text {-ref, }}$ see (8). The rate of change of $\Delta i_{q-\text { ref }} / \Delta i_{\text {d-ref }}$ (8) increases until it reaches $\infty$ when $i_{q}$ approaches 0 . This high value of $\Delta i_{q-\text { ref }} / \Delta i_{d-r e f}$ causes the unstable area shown in Fig. 7.

It is therefore proposed to modify the current limiting model (3) (which is a circle trajectory) to limit the value of $\Delta i_{q-\text {-ref }} / \Delta i_{d-\text {-ref }}$ (the gradient of the circle trajectory) when $\mathrm{i}_{\mathrm{q}-\text {-ref }}$ is small in generating mode only. This is a novel addition to the control strategy. The proposed current limiting trajectory is given by the thick red line shown in Fig. 9 and is defined by the angle $\phi$ and $I_{\max }$.

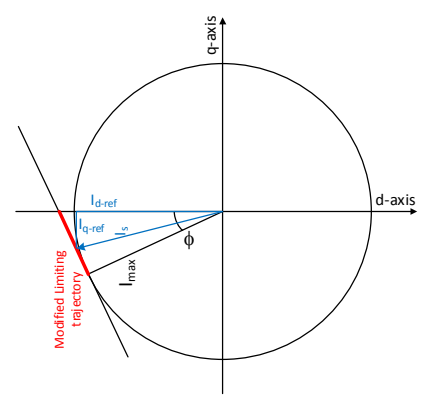

Fig. 9 Proposed current limiting trajectory.

The angle $\phi$ is a specific angle (position) of the PMM current vector at which the proposed limiting trajectory is enabled to calculate $\mathrm{i}_{\mathrm{q}-\text {-ref }}$ instead of (3). The value of the angle $\phi$ is the one at which $\mathrm{i}_{\text {q-ref }}$ is equal to two times $\mathrm{i}_{\mathrm{q} \text {-crt }}(15)$ or when $\mathrm{I}_{\max }=\mathrm{I}_{\mathrm{Imt}}$ (see (17)). This is to give sufficient margin for the control system to switch from (3) to the modified current limiting trajectory before reaching the unstable area. Hence, from Fig. 9, (14) and (16):

$$
\tan (\phi)=\frac{2 R_{s}}{0.5 \omega_{r e}\left(L_{d}+L_{q}\right)}
$$

By the analysis of the blue-line triangle in Fig. 9, $\mathrm{i}_{\mathrm{q}-\text { ref }}$ is calculated from the proposed trajectory (red line) as:

$$
i_{q-r e f}=-\frac{I_{\max }}{\sin (\phi)}-i_{d-r e f} \tan (90-\phi)
$$

hence the small signal model of (19) is:

$$
\frac{\Delta i_{q-r e f}}{\Delta i_{d-r e f}}=-\tan (90-\phi)
$$


which is a constant value for a given speed. The boundary limit $\mathrm{k}_{\mathrm{iv}-\mathrm{lm} 4}$ at different speeds is plotted in Fig. 10 when using only the current limiter (3). Fig. 11 shows the resultant stabilised result when using the proposed current limiting trajectory (19). It is clearly seen that the proposed current limiting technique has a crucial stabilising effect on system: if the unstable area of operation in Fig. 10 increases with the speed, in Fig. 11 it is completely eliminated when the proposed variable current limiting mechanism is employed.

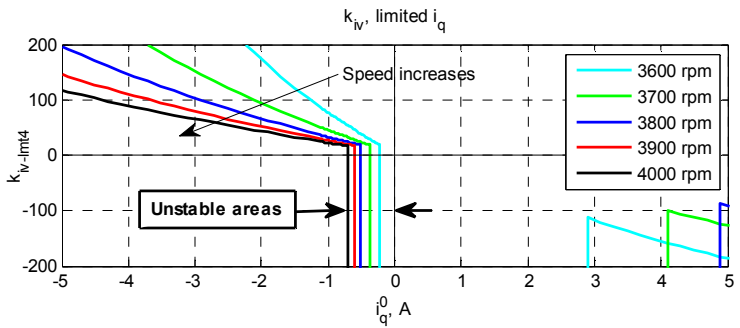

Fig. 10 Unstable area in limited iq and generating mode using the current limiting model (3) only.

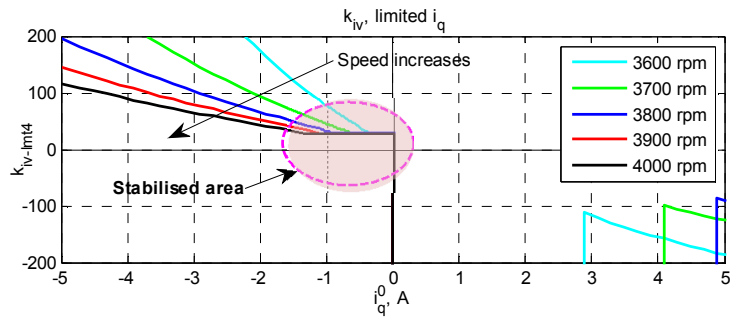

Fig. 11 Stabilisation of voltage control loop in limited $i_{q}$ and generating mode using the proposed variable current limit (19).

Summarizing previous Sections, the conducted small-signal stability analysis and control design for FW voltage control of PMMs have shown that the voltage control loop is nonminimum phase in unlimited $i_{q}$ mode while it is minimum phase in generating mode. While in limited $\mathrm{i}_{\mathrm{q}}$ in generating mode, the voltage control loop is unstable if $\mathrm{i}_{\mathrm{q}-\text { ref }}$ is small. $\mathrm{A}$ variable current limit method is proposed to eliminate the intrinsic instability of the voltage control. $\mathrm{k}_{\mathrm{iv}}$ is adaptively adjusted to maintain operation in the stable areas and to provide good dynamic performance.

These main findings of the stability analysis and control design are experimentally validated in the next section.

\section{Experimental Investigation and Validation}

An experimental test rig including a $3 \mathrm{~kW}$ PMM was built in order to validate the small signal modelling, stability analysis and control design presented in the previous sections. The PMM is connected to a commercial 4Q DC drive that acts as an active load. The PMM is driven by a PWM converter with $12.5 \mathrm{kHz}$ switching frequency and controlled by a DSP/FPGA control platform. Various test scenarios are implemented to validate the main findings of the theoretical study.

\subsection{Stability Analysis Validation Testing}

The obtained stability boundary limits for $\mathrm{k}_{\mathrm{iv}}$ given in the previous sections will be validated in this section for unlimited and limited $\mathrm{i}_{\mathrm{q}}$ modes respectively.

\section{Unlimited $i_{q}$ case}

In order to investigate the $\mathrm{k}_{\text {iv }}$ stability limit given in Fig. 8, the PMM is driven at $3600 \mathrm{rpm}(105 \%$ of nominal speed) and operated in unlimited $\mathrm{i}_{\mathrm{q}}$ control mode with $\mathrm{i}_{\mathrm{q}-\text { ref }}=4 \mathrm{~A}$ (motoring mode, $\sim 50 \%$ load). The voltage reference is constant and equal to $250 \mathrm{~V}$. The value of $\mathrm{k}_{\mathrm{iv}}$ is set to 650 , just below the stability boundary limit, and then changed to 700 to hit the limit. The experiment results are shown in Fig. 12. It can be seen that the system is stable at $\mathrm{k}_{\mathrm{iv}}=650$ and becomes unstable after the change of $\mathrm{k}_{\text {iv }}$ at $\mathrm{t} \sim 0.422 \mathrm{~s}$. This result confirms the stability analysis shown in Fig. 8 and proves the non-minimum phase behavior of the PMM voltage control loop in motoring mode with unlimited $\mathrm{i}_{\mathrm{q}}$

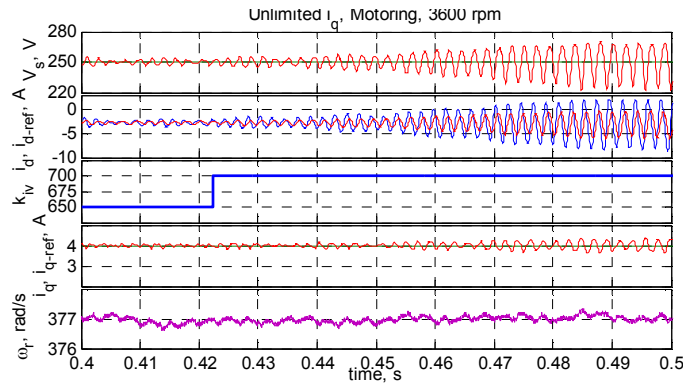

Fig. 12 Experimental validation of kiv stability limit for unlimited $i_{q}$ and motoring mode of operation.

The test was repeated under generating mode with $\mathrm{i}_{\mathrm{q}-\mathrm{ref}}=-4 \mathrm{~A}$ $\mathrm{k}_{\mathrm{iv}}$ is changed from 100 to 1000 . The experimental results are shown in Fig. 13. It can be seen that the voltage control remains stable after the change of $\mathrm{k}_{\text {iv }}$ at $\mathrm{t} \sim 0.388 \mathrm{~s}$. As with the previous test, this experimentally confirms the small signal analysis given in Fig. 8 and proves the minimum phase behaviour of the system in generating mode with unlimited $\mathrm{i}_{\mathrm{q}}$.

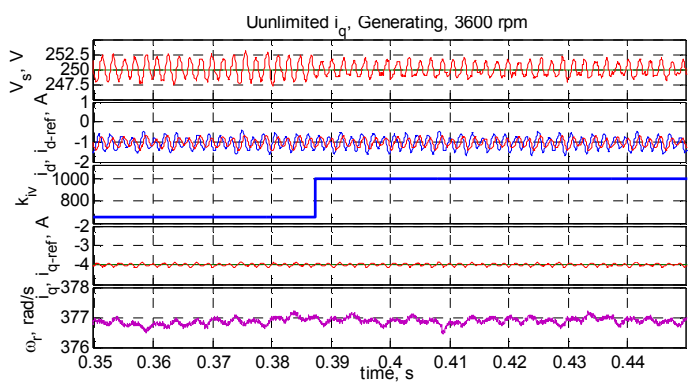

Fig. 13 Experimental validation of $\mathrm{k}_{\mathrm{iv}}$ stability limit for unlimited $\mathrm{i}_{\mathrm{q}}$ and generating mode of operation.

\section{Limited $i_{q}$ Case}

In this test, the stability boundary limit for $\mathrm{k}_{\mathrm{iv}}$ at point $\mathrm{B}$ in Fig. 7 will be validated during generating mode with limited $\mathrm{i}_{\mathrm{q}}$. The PMM is again operated at $3600 \mathrm{rpm}$ with the voltage reference set to $250 \mathrm{~V}$. In limited $\mathrm{i}_{\mathrm{q}}$ mode, (3) is used for the current limiting. $\mathrm{I}_{\max }$ is set to $4.5 \mathrm{~A}$ which results in $\mathrm{i}_{\mathrm{q}-\mathrm{ref}}=-4 \mathrm{~A} . \mathrm{k}_{\mathrm{iv}}$ is first set $=400$ and then changed to 550 to cross point $\mathrm{B}$ in Fig. 7 . The obtained experimental results are shown in Fig. 14. It is found that the voltage control becomes unstable after changing $\mathrm{k}_{\mathrm{iv}}$ to 550 (at $\mathrm{t} \sim 0.544 \mathrm{~s}$ ), which therefore experimentally validates the theoretical stability boundary limit shown in Fig. 7 (see point B). 


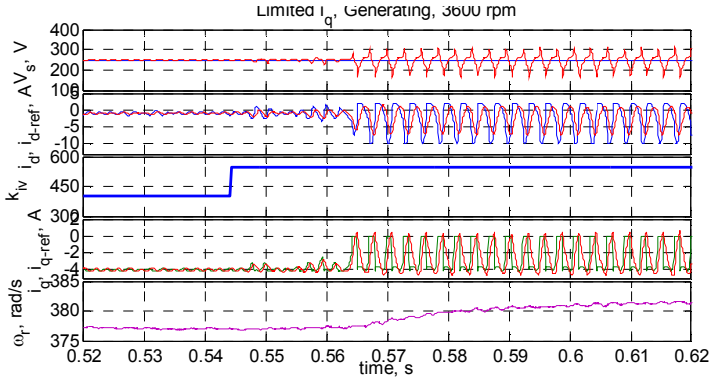

Fig. 14 Experimental validation of $\mathrm{k}_{\mathrm{iv}}$ stability limit for limited $\mathrm{i}_{\mathrm{q}}$ and generating mode of operation.

The test was repeated under motoring mode with $\mathrm{i}_{\mathrm{q}-\mathrm{ref}}=4 \mathrm{~A}$. The gain $\mathrm{k}_{\mathrm{iv}}$ was changed from 100 to 1000 . The obtained test results show the system operates stably after the change of $k_{\text {iv }}$ to 1000 . This experimentally confirms the minimum phase behaviour of the voltage control loop in limited $\mathrm{i}_{\mathrm{q}}$ and motoring mode.

\subsection{Validation of Adaptive $k_{i v}$ Gain}

In this test, the smooth and stable transition of the operating point from generating to motoring mode, using the adaptive gain and the current limiting (19) was investigated.

The adaptive gain $\mathrm{k}_{\mathrm{iv}-a d a p t}$ model (16) is implemented using a lookup table mapped against the motor speed and $\mathrm{i}_{\mathrm{q}-\text { ref. }} \mathrm{k}_{\mathrm{iv}}$ is adaptively changed within minimum and maximum limits equal to 15 and 100. At the beginning of the test, the PMM is operated at $3700 \mathrm{rpm}$ in generating mode with $\mathrm{I}_{\max }=4 \mathrm{~A}$. Then, $\mathrm{I}_{\max }$ is slowly decreased to $1.7 \mathrm{~A}$ within $1 \mathrm{~s}$ and remains fixed at $1.7 \mathrm{~A}$ for a further $1 \mathrm{~s}$. Afterwards, the operating mode is changed to motoring (at $\mathrm{t}=2.3 \mathrm{~s}$ ) and $\mathrm{I}_{\max }$ is gradually increased from $1.7 \mathrm{~A}$ to $4.5 \mathrm{~A}$. The results of the experiment are shown in Fig. 15. The results show stable operation even at small $\mathrm{I}_{\max }$. In addition, the PMM also transfers smoothly from generating to motoring mode. Note that there are oscillations in the $\mathrm{i}_{\mathrm{d}}$ and $\mathrm{i}_{\mathrm{q}}$ currents during the period $2.7 \mathrm{~s}$ to $3.3 \mathrm{~s}$. These oscillations are due to disturbances originated from the DC drive controller during regenerative mode and have no link with the voltage control loop of the PMM.

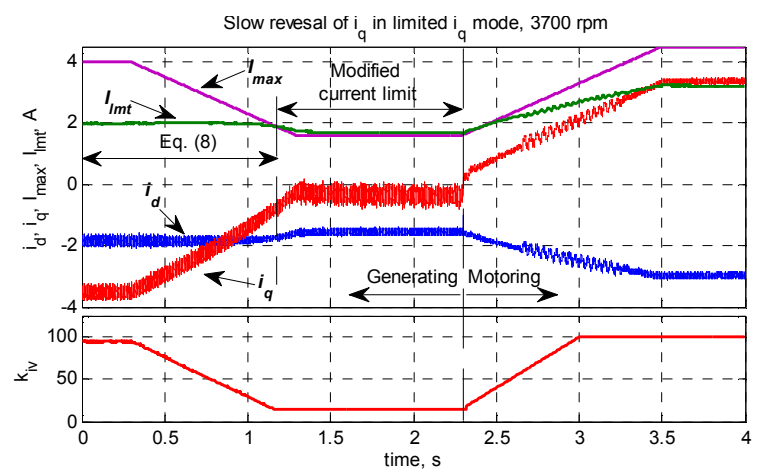

Fig. 15 Experimental investigation of modified current trajectory and adaptive kiv.

The experimental results shown in Fig. 15 confirm the importance of using the adaptive $\mathrm{k}_{\mathrm{iv}}$ and the proposed variable current limit to achieve stable voltage control in limited $\mathrm{i}_{\mathrm{q}}$ and generating mode.

\section{Conclusions}

The paper has reported detailed analysis and control design for a PMM-based aircraft starter-generator operated in FW mode. The FW control of the PMM was found to have intrinsic instability with small $\mathrm{i}_{\mathrm{q}}$ in generating and limited current mode. This is due to the high gradient of the traditional circle based current limiting trajectory used in FW. A new variable current limit with reduced gradient at small $\mathrm{i}_{\mathrm{q}}$ is proposed and the approach is analytically proven to eliminate these unstable areas. Also, an adaptive voltage controller is designed to achieve good dynamic performance irrespective of the operating point of the PMM. The designed adaptive voltage controller with the new current limit approach has guaranteed stable operation in various operating modes of the PMM. The analytical small signal based analysis and the proposed control design with the expected system performance were successfully verified and validated by experimental investigation.

\section{References}

[1]. B. Bose, "Global energy scenario and impact of power electronics in 21st century," Industrial Electronics, IEEE Transactions on, Vol.60, No.7, 2013.

[2]. I. Moir, and A. Seabridge, "Aircraft systems: Mechanical, electrical, and avionics subsystems integration", John Wiley \& Sons, 2008

[3]. P. C.Krause, O. Wasynczuk, and S. D. Sudhoff, Analysis of electric machinery and dirve systems: Wiley-interscience, 2002.

[4]. Leonhard.W, "Adjustable-speech AC drives", Proceeding of the IEEE, vol.76, No. 4

[5]. M S. Morimoto, Y. Takeda, T. Hirasa, K. Taniguchi, "Expansion of operating limits for permanent magnet motor by current vector control considering inverter capacity", IEEE Trans. Industry Applications, Vol.26, No.5, Sept./Oct. 1990, pp. 866-871.

[6]. G. Gallegos-Lopez, et al., "Optimum torque control of permanent-magnet AC Machines in the field-weakened region," Industry Applications, IEEE Transactions on, Vol. 41, 2005, pp. 1020-1028.

[7]. L. Zhu, et al., "Deep field-weakening control of PMSMs for both motion and generation operation," in Electrical Machines and Systems (ICEMS), 2011 International Conference on, 2011, pp. 1-5.

[8]. Ping-Yi and L. Yen-Shin, "Voltage Control Technique for the Extension of DC-Link Voltage Utilization of Finite-Speed SPMSM Drives," Industrial Electronics, IEEE Transactions on, vol. 59, 2012, pp. 3392-3402.

[9]. S. Jong-Hwan, et al., "A new robust SPMSM control to parameter variations in flux weakening region", Proceedings of the 1996 IEEE IECON 22nd International Conference on Industrial Electronics, Control, and Instrumentation, Vol. 2, 1996.

[10].S. Maric, et al., "Two improved flux weakening schemes for surface mounted permanent magnet synchronous machine drives employing space vector modulation," in Industrial Electronics Society, 1998. IECON '98. Proceedings of the 24th Annual Conference of the IEEE, vol.1, 1998.

[11].S. Bolognani, S. Calligaro and R. Petrella, "Adaptive Flux-Weakening Controller for Interior Permanent Magnet Synchronous Motor Drives", IEEE Joutnal of Emerging and Selected Topics in Power Electronics, Vol. 2, No. 2, JUNE 2014, pp. 236-248.

[12].D. Stojan, D. Drevenšek, Z. Plantic, B. Grcar, and G. Štumberger, "Novel field-weakening control scheme for permanent-magnet synchronous machines based on voltage angle control," IEEE Trans. Ind. Appl., vol. 48, no. 6, pp. 2390-2401, Nov./Dec. 2012.

[13]. M. Rashed, P.F.A. MacConnell, A.F. Stronach and P. Acarnley, "Sensorless Indirect-Rotor-Field-Orientation Speed Control of a Permanent-Magnet Synchronous Motor with Stator-Resistance Estimation", IEEE Transactions on Industrial Electronics, Vol. 54, No. 3, 2007, pp. 1664-1675.

\section{Appendix I. PMM and Control Parameters}

$\mathrm{p}=3, \mathrm{R}_{\mathrm{s}}=1.25 \Omega, \mathrm{L}_{\mathrm{d}}=6.17 \mathrm{mH}, \mathrm{L}_{\mathrm{q}}=8.38 \mathrm{mH}, \psi_{\mathrm{r}}=0.23 \mathrm{~Wb}, \omega_{\mathrm{rn}}=$ $3400 \mathrm{rpm}, \mathrm{k}_{\text {pid }}=12.28, \mathrm{k}_{\text {iid }}=8428.3, \mathrm{k}_{\mathrm{piq}}=15.99, \mathrm{k}_{\text {iiq }}=10724$. 